\title{
A Single FIA System Coupled with Reduction and Distillation Processes for the Determination of Sulfate Ion by Spectrophotometry
}

\author{
Ariadne M. Brondi,* Giovana F. Lima,* Célio WisniEwski, ** Maria J. S. WisniewSKI,*** and \\ Pedro O. LuCCAS $* *$ \\ *Universidade Federal de Alfenas, Instituto de Química, R. Gabriel Monteiro da Silva, 714, 37130-000 \\ Alfenas-MG, Brasil \\ **Universidade Federal de Alfenas, Instituto de Ciências Exatas, R. Gabriel Monteiro da Silva, 714, \\ 37130-000 Alfenas-MG, Brasil \\ ***Universidade Federal de Alfenas, Instituto de Ciências da Natureza, R. Gabriel Monteiro da Silva, 714, \\ 37130-000 Alfenas-MG, Brasil
}

\begin{abstract}
In the present work, all steps of the sulfate reduction procedures, such as reduction, distillation and sulfate determination were joined in only one FIA system. The formed sulfide was on-line determined by employ the Fisher reaction. The

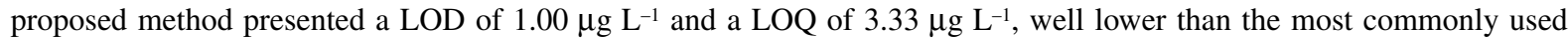
turbidimetric determination, with no significant interferences. Additionally, we reached an analytical frequency of 6 measurements per hour, including all steps, beginning with the introduction of the sample up to the signal reading. Therefore, it revealed very fast, low reagent/sample consumption, agreeing with green-chemistry statements. This method has also a wide linear range (3.33 up to $\left.1000 \mu \mathrm{g} \mathrm{L}^{-1}\right)$, being useful for both low and high sulfate concentrations.
\end{abstract}

(Received January 29, 2013; Accepted March 23, 2013; Published May 10, 2013)

\section{Introduction}

Sulfate is the most stable and abundant form of sulfur found in nature. The largest amount of sulfur is assimilated by living organism in this form. However, due to anthropogenic sources, the amount of sulfate in aquatic ecosystems has increased, substantially upsetting natural ecosystems, and causing serious damage. Thus, in water quality studies sulfate determination is very important. In recent years, attention has been focused on the impact sulfate pollution, being seen as an issue inconcerning inland aquatic ecosystems management. ${ }^{1,2}$

Among the most common methods for sulfate determination is gravimetric ${ }^{3}$ which is relatively laborious, and therefore inadequate to do determinations of a higher number of samples. The FIA system with turbidimetric detection shows good results for water analysis; however, suspension instability is a problem need to be overcome. ${ }^{4}$ Sulfate determination in water samples by ionic chromatography is one very useful alternative. ${ }^{5}$ ICP-OES can also be useful for sulfate determination in water; however, this technique is indirect, and measures the sulfur concentration, not sulfate. Therefore, the main limitation is interference caused by other sulfur compounds. ${ }^{6,7}$

In this work a FIA system used for the reduction, distillation and determination of sulfate (all in only one FIA system) was proposed. The method is based on our previous work, ${ }^{8}$ in which sulfide was determined. The FIA system has a mini-reactor to which hydroiodic is added for the reduction of sulfate to sulfide.

$\dagger$ To whom correspondence should be addressed.

E-mail: pedro.luccas@unifal-mg.edu.br
The formed sulfide is carried and merged with the diethylphenylenediamine (DEPD) and $\mathrm{FeCl}_{3}$ reagents to form a methylene blue compound, which is detected in a spectrophotometer. $^{9}$

The two main advantages of the proposed system are: i) rapidity in determining, because the samples are only filtered and introduced in the system with no more additional treatment; ii) improvement in the sensibility, because the available spectrophotometric methods for sulfate determination have a detection limit in the range of $\mathrm{mg} \mathrm{L}^{-1}$; on the other hand, in sulfide (or sulfate reduced) detection, a limit of up to $\mu \mathrm{g} \mathrm{L}^{-1}$ can be reached. ${ }^{8}$

The idea to reduce sulfate to sulfide for subsequent determination of the latter is an old one, ${ }^{10,11}$ nevertheless, up to now each step has been performed separately, making the method slow and showing poor accuracy. In the present work, the FIA system provided: speed, better precision and accuracy, lower cost, and less susceptibility to sample contamination.

In order to optimize this method, the more used way is a monovariate method, which consists of studying one variable while maintaining the others at fixed values. This tool demands a higher number of experiments since the optimized values for all variable are actually not always the best. As an alternative to monovariate, a multivariate tool has been used, whose main features are:12,13 i) optimization with a lower number of experiments; ii) simultaneous checking the effects of all variables (as well as whether there are interactions among them); iii) the optimum values are more trusted than the monovariate procedures.

In this work, a chemometric tool, Central Compost Design (CCD) to construct mathematical (quadratic) models, and to 


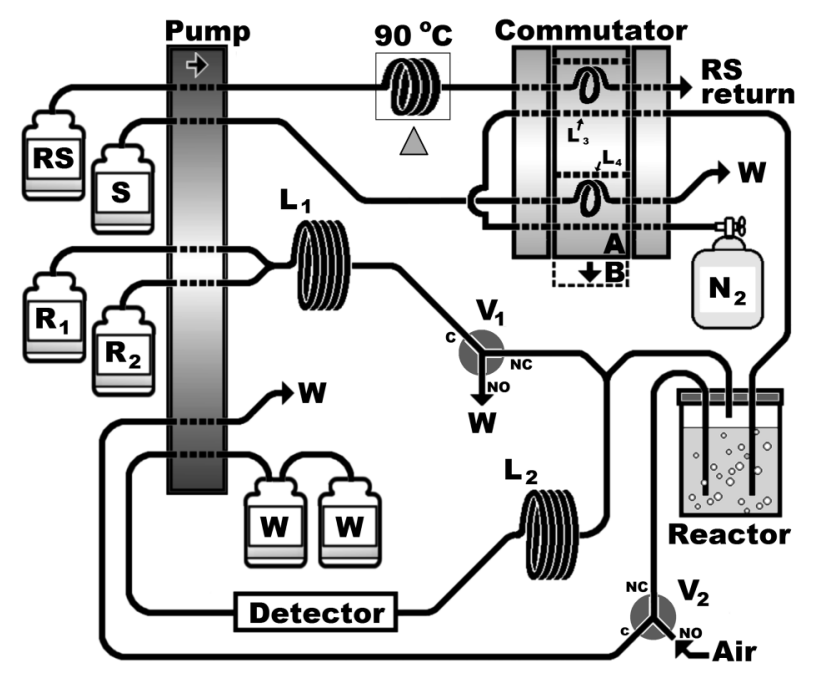

Fig. 1 Manifold of the flow system for sulfate determination. A, Sampling step; B, insertion of the sample step; S, sample; RS, reducing solution; R1, $0.5 \mathrm{~mL} \mathrm{~min}^{-1}$ of DEPD $4.09 \mathrm{~g} \mathrm{~L}^{-1}$; R2, $0.5 \mathrm{~mL} \mathrm{~min}^{-1}$ of $\mathrm{Fe}^{3+} 0.02 \mathrm{~mol} \mathrm{~L}^{-1}$ in $\mathrm{H}_{2} \mathrm{SO}_{4} 0.04 \mathrm{~mol} \mathrm{~L}-1$; $\mathrm{L}$, reactor coil of $150 \mu \mathrm{L}$; $\mathrm{L} 2$, reactor coil of $700 \mu \mathrm{L} ; \mathrm{L} 3$, reagent loop $(630 \mu \mathrm{L})$; L4, sample loop $(535 \mu \mathrm{L}) ; \mathrm{W}$, waste bottle with zinc acetate $3 \%(\mathrm{w} / \mathrm{v})$ and $\mathrm{N}_{2}$ (400 mL/min); V1 and V2, solenoid valves, (valve pattern: NC, normal closed; NO, normal open; C, common).

calculate the optimal values was used. ${ }^{12}$ The advantages of chemometrics tools, as well as those of automation with the FIA system, can be observed in the present work.

\section{Experimental}

\section{Reagents and chemicals}

All solutions were prepared with distilled and deionized water (Milli-Q Systems, Millipore). The $N, N$-diethyl- $p$-phenylenediamine (DEPD, Fluka) and $\mathrm{FeCl}_{3} \cdot 6 \mathrm{H}_{2} \mathrm{O}$ (Synth) were prepared by dissolution of corresponding salts in an aqueous solution of $\mathrm{H}_{2} \mathrm{SO}_{4} 0.025 \mathrm{~mol} \mathrm{~L}^{-1}$ (Merck). The reducing solution, described by Johnson and Nishita, ${ }^{10}$ was prepared by mixing $40 \mathrm{~mL}$ of $\mathrm{HI}$ (Vetec) and $2.5 \mathrm{~mL}$ of $\mathrm{H}_{3} \mathrm{PO}_{4}$ (Vetec), plus $20 \mathrm{~mL}$ of acetic acid (Synth), leaving it at $100^{\circ} \mathrm{C}$ for $1 \mathrm{~h}$. Zinc acetate solution was prepared by dissolving $\left(\mathrm{CH}_{3} \mathrm{COO}\right)_{2} \mathrm{Zn} \cdot 2 \mathrm{H}_{2} \mathrm{O}$ crystallized PA (Proquimios) in water. A sulfate stock solution, $1000 \mathrm{mg} \mathrm{L}^{-1}$, was prepared by dissolution of salt $\mathrm{Na}_{2} \mathrm{SO}_{4}$ (Synth) in an aqueous solution of $\mathrm{HCl} 0.025 \mathrm{~mol} \mathrm{~L}^{-1}$ (Merck). The sulfate salt was previously dried at $105^{\circ} \mathrm{C}$ for $24 \mathrm{~h}$. Nitrogen gas (White Martins) was used in the multisegmented FIA system.

\section{Apparatus}

The FIA system was built using a peristaltic pump (Ismatec IPC-08) with Tygon ${ }^{\circledR}$ tubes to propel the fluids, and polyethylene tubes with an internal $0.8 \mathrm{~mm}$ diameter to drive the fluids. Two three-way solenoid valves (Research-NR) were used to commutate the flows. The spectrophotometric measures were carried out using an Ocean Optics Spectrophotometer USB 4000 (UV-Visible). Data acquisition was performed by using the Spectra Spectroscopy Software Suite from Ocean Optics. To control the FIA system, a PCL-711 interface (Advantech ${ }^{\circledR}$ ) was used.

A mini-reactor (Fig. 1) was built with a $1.5-\mathrm{ml}$ polyethylene tube (Eppendorf). The reducing solution was heated to $90^{\circ} \mathrm{C}$ by immersing a $400-\mathrm{cm}$ loop in a water bath during the time in which the determination was performed.

\section{Flow-injection analysis manifold}

The FIA system was similar to the preceding one,${ }^{8}$ as shown in Fig. 1. The solenoid valve 1 works while alternating constantly: $2 \mathrm{~s}$ to insert the chromogenic reagent, and $12 \mathrm{~s}$ to insert nitrogen gas. The automatic commutator has two loops: one for the reducing reagent $\left(\mathrm{L}_{3}\right)$ and the other for the sample $\left(\mathrm{L}_{4}\right)$. In the first step (sampling step, A position), the commutator was maintained for $90 \mathrm{~s}$ to fill the loops. In the second step (B position, $400 \mathrm{~s}$ ), the loops contents were carried by a nitrogengas stream $\left(400 \mathrm{ml} \mathrm{min}^{-1}\right)$ into the mini-reactor to proceed the reducing sulfate to sulfide. The $\mathrm{H}_{2} \mathrm{~S}$ generated was carried by nitrogen, and received the reagents in valve 1 ; when the zone sample reached the cuvet (in $\mathrm{Z}$ shape), the signal was obtained by the spectrophotometer. In the third and last step, the valve 2 was started (40 s), cleaning the mini-reactor.

\section{Optimization procedure}

To optimize the sample volumes (SL) and reducing solution (RL), CCD was used. ${ }^{12,13}$ The experimental data were processed using the STATISTICA (StatSoft, Tulsa, USA) program, setting the statistical significance with a $95 \%$ confidence level. All of the other factors were the same as those in Lima et al. ${ }^{9}$ nitrogen at a flow-rate of $400 \mathrm{~mL} \mathrm{~min}^{-1}$; DEPD $4.09 \mathrm{~g} \mathrm{~L}^{-1}$ at a flow-rate of $0.5 \mathrm{~mL} \mathrm{~min}^{-1} ; \mathrm{Fe}^{3+} 0.020 \mathrm{~mol} \mathrm{~L}^{-1}$ in $\mathrm{H}_{2} \mathrm{SO}_{4} 0.04 \mathrm{~mol} \mathrm{~L}^{-1}$ at a flow-rate of $0.5 \mathrm{~mL} \mathrm{~min}^{-1}$; volume of $150 \mu \mathrm{L}$ for the reagents coil $\left(\mathrm{L}_{1}\right)$; volume of $700 \mu \mathrm{L}$ for the reaction coil $\left(\mathrm{L}_{2}\right)$ and flow for cleaning the cell (FC) at a rate of $2.5 \mathrm{~mL} \mathrm{~min}^{-1}$. The peak area was used as the analytical signal.

\section{Application in water samples}

Water samples were collected from mines and lakes in the town of Alfenas, State of Minas Gerais, Brazil. The collection procedures are described in the Brazilian National Council on the Environment (CONAMA). ${ }^{14}$ Therefore, to acidify/preserve the sample, one $\mathrm{mL}$ of $14 \mathrm{~mol} \mathrm{~L}^{-1}$ of nitric acid for each liter of water at the moment of collection was used. The samples were maintained in refrigeration for no longer than one week, until determination.

\section{Results and Discussion}

\section{Analytical signal}

In the proposed system (Fig. 1) there is no device to remove bubbles. Therefore, noise is observed in the analytical signal (Fig. 2), caused by the interaction of radiation with the gas bubbles and solution. For signal noise elimination, the OriginPro 8 software was employed. ${ }^{9}$ After it was treated, the peak area of each signal was also calculated with OriginPro 8 software.

\section{Optimization study}

The CCD involving two factors consists of 11 assays, including triplicates on the central point. ${ }^{13}$ The assays were executed randomly so as to avoid systematic errors, and the data were processed with the STATISTICA (Ver. 6.0) software package (StatSoft, Tulsa, USA), establishing a 95\% confidence level. With the CCD design results, a quadratic model was built and allowed to plot a response surface graphic (Fig. 3). The analysis of variance (ANOVA) indicated that $99.89 \%$ of the model can be explained by regression at the $95 \%$ confidence level.

The response surface, Fig. 3, allows observing that the signal is directly proportional to reducing the solution volumes, as well 


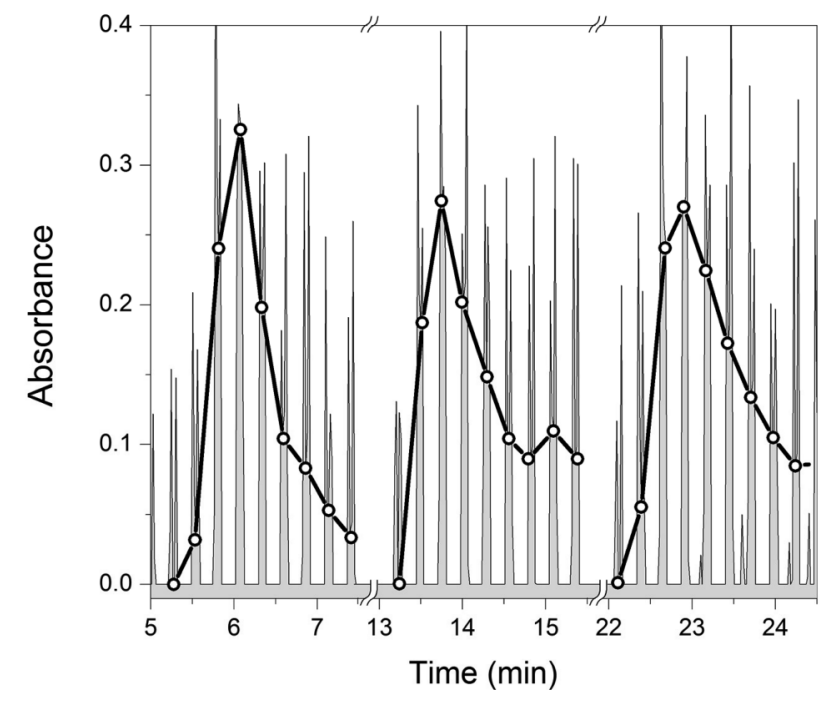

Fig. 2 Signal record in triplicate for $500 \mu \mathrm{g} \mathrm{L}^{-1}$ of the sulfate standard solution under the optimized conditions.

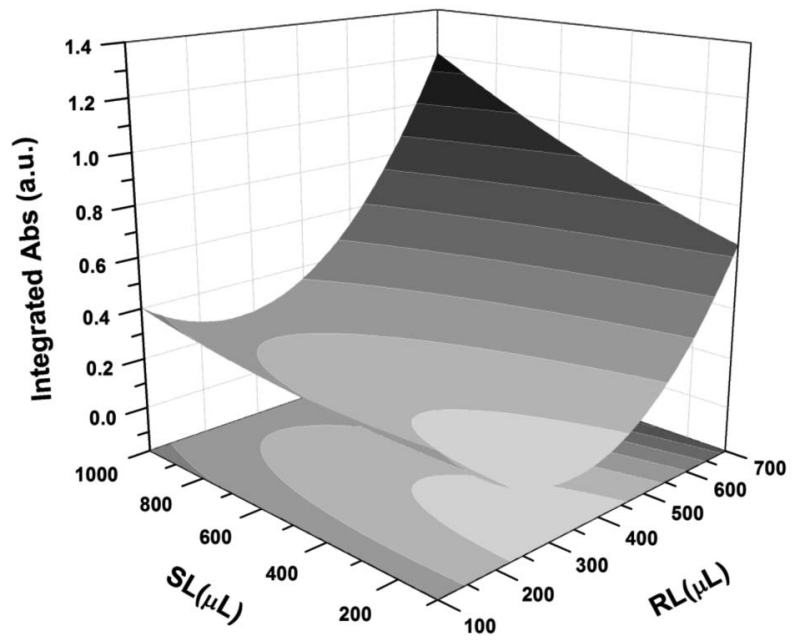

Fig. 3 Response surface for the volume of the reducing solution loop (RL) versus the sample volume loop (SL), results from CCD experiments.

as the sample volume. Nevertheless, the mini-reactor has a maximum volume of $1.5 \mathrm{~mL}$, thus making it impossible to increase the values for these variables. Therefore, volumes of 630 and $535 \mu \mathrm{L}$ for the reducing solution and sample were adopted, respectively, because this combination provided the best analytical signal and guarantees that the sulfate was reduced.

\section{Interference studies}

The presence of some concomitants may cause positive or negative changes in the analytical response. There is the possibility for the formation of volatile compounds, which would be able to react with DEPD, or for the formation of insoluble compounds with the sulfate and/or sulfide generated in situ by chemical reduction. Thus, ions that are commonly encountered in natural water, such as: $\mathrm{S}^{2-}, \mathrm{Ba}^{2+}, \mathrm{Cu}^{2+}, \mathrm{Cl}^{-}, \mathrm{Fe}^{3+}$, $\mathrm{Fe}^{2+}, \mathrm{Cd}^{2+}, \mathrm{Zn}^{2+}, \mathrm{Ag}^{+}, \mathrm{F}^{-}, \mathrm{Na}^{+}$and $\mathrm{NO}_{3}^{-}$, were evaluated. Binary mixtures constituted by sulfate $\left(300 \mu \mathrm{g} \mathrm{L}^{-1}\right)$ and concomitants

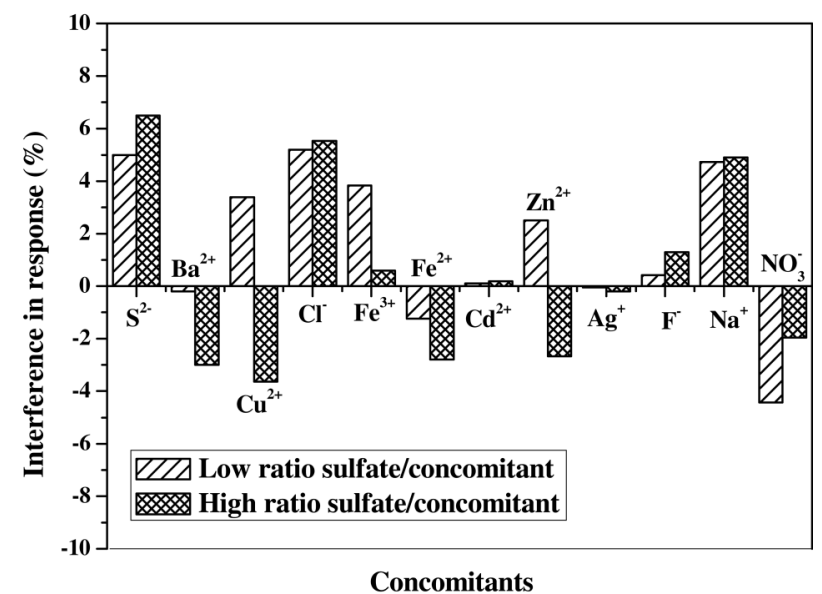

Fig. 4 Foreign ions effect on $300 \mu \mathrm{g} \mathrm{L}^{-1}$ of the sulfate analytical signal. The concentrations (low/high, in $\mu \mathrm{g} \mathrm{L}^{-1}$ ) were $\mathrm{S}^{2-}(150 / 600)$, $\mathrm{Ba}^{2+}(500 / 2000), \quad \mathrm{Cu}^{2+}(6.5 / 26), \quad \mathrm{Cl}^{-} \quad(125000 / 500000), \quad \mathrm{Fe}^{3+}$ (2500/10000), $\mathrm{Fe}^{2+}(2500 / 10000), \mathrm{Cd}^{2+}(5 / 20), \mathrm{Zn}^{2+}$ (2500/10000), $\mathrm{Ag}^{+}$ (25/100), $\mathrm{F}^{-}(700 / 2800), \mathrm{Na}^{+}(300 / 10000)$ and $\mathrm{NO}_{3}{ }^{-}(5000 / 20000)$.

ions, were prepared.

The concentrations of potential concomitants were based on the maximum level permitted (MLP) in water by Brazilian National Council on the Environment (CONAMA). ${ }^{14}$ In this way, one concentration below and one above the MLP were tested. Thus, the tested concentrations (low/high, in $\mu \mathrm{g} \mathrm{L}^{-1}$ ) were $\mathrm{S}^{2-}(150 / 600), \mathrm{Ba}^{2+}(500 / 2000), \mathrm{Cu}^{2+}(6.5 / 26), \mathrm{Cl}^{-}$ (125000/500000), $\mathrm{Fe}^{3+}(2500 / 10000), \mathrm{Fe}^{2+}(2500 / 10000), \mathrm{Cd}^{2+}$ (5/20), $\mathrm{Zn}^{2+}(2500 / 10000), \mathrm{Ag}^{+}(25 / 100), \mathrm{F}^{-}$(700/2800), $\mathrm{Na}^{+}$ (300/10000) and $\mathrm{NO}_{3}{ }^{-}(5000 / 20000)$. In this work, it was considered to be an interferent if concomitant modified the signal by at least $\pm 10 \%$.

The analytical signal recovery percentage (\%), when compared to the standard solution containing only $\mathrm{SO}_{4}{ }^{2-}$, showed no influence of the concomitants (Fig. 4). These results suggest a good tolerance to the presence of foreign ions, even at high concentrations. This non interference can be attributed to the distillation step, which separates the analyte from the majority of concomitants. Thus, it is worth mentioning that the proposed method overcame the limitation reported for other methods in order to provide satisfactory selectivity to water samples.

\section{Figures of merit and application}

It is important to stress that, in our previous work, ${ }^{8}$ the sulfite determination was done using a similar system, thus based on sensibility $(0.2218$ and 0.0783 for sulfide and sulfate determinations, respectively) and the stoichiometry ratio reactions (3:1). It can be inferred that the sulfate to sulfite conversion is about $94 \%$.

The samples were collected and acidified with $1 \mathrm{ml}$ of $\mathrm{HNO}_{3}$ per each sample liter, and filtered with a $0.45-\mu \mathrm{m}$ membrane. In the laboratory, each measurement took $9 \mathrm{~min}$, being $90 \mathrm{~s}$ to fill the loops and $440 \mathrm{~s}$ to read the signal and to clean the minireactor, thus, at a rate of about 6.7 measurements per hour.

To describe the FIA system for sulfate analytical performance determination under the optimum conditions, we investigated the following figures of merit: linear range, limits of detection and quantification, precision, accuracy and frequency of reading. The proposed method presented an analytical curve with two linear regions, the first being in the range of 3.33 to $1000 \mu \mathrm{g} \mathrm{L}^{-1}$ $\left(R^{2}=0.994\right)$ and the second in the range of 1 to $10 \mathrm{mg} \mathrm{L}^{-1}$ 
Table 1 Recovery tests in water samples

\begin{tabular}{|c|c|c|c|}
\hline Sample & $\begin{array}{l}\text { Concentration of } \\
\mathrm{SO}_{4}{ }^{2-} \text { added } / \mu \mathrm{g} \mathrm{L}\end{array}$ & $\begin{array}{l}\text { Concentration of } \\
\mathrm{SO}_{4}{ }^{2} \text { found } / \mathrm{mg} \mathrm{L}^{-1}\end{array}$ & $\begin{array}{c}\text { Recovery, } \\
\%\end{array}$ \\
\hline \multirow[t]{2}{*}{ Mine water } & 0 & $7.81 \pm 0.48$ & - \\
\hline & 300 & $8.06 \pm 0.69$ & 99 \\
\hline \multirow[t]{2}{*}{ Dam water 1} & 0 & $11.89 \pm 0.56$ & - \\
\hline & 300 & $12.27 \pm 0.66$ & 101 \\
\hline \multirow[t]{2}{*}{ Dam water 2} & 0 & $4.98 \pm 0.56$ & - \\
\hline & 300 & $5.17 \pm 0.71$ & 98 \\
\hline
\end{tabular}

The results are expressed as mean \pm standard deviation $(n=3)$.

$\left(R^{2}=0.988\right)$. The detection limit $\left(1.00 \mu \mathrm{g} \mathrm{L}^{-1}\right)$ and quantification limit $\left(3.33 \mu \mathrm{g} \mathrm{L}^{-1}\right)$ were based on the standard deviations of ten blank readings (std) and the slope of an analytical curve (m). ${ }^{15}$ Thus, for LOD, equaling to $3 . \mathrm{std} / \mathrm{m}$ and for $\mathrm{LOQ}$, equaling to $10 . \mathrm{std} / \mathrm{m} .{ }^{14}$ The precision was evaluated as the relative standard deviation $(n=10)$, and was found to be $1.5,2.1$ and $1.8 \%$ for sulfate concentrations of 150 and $500 \mu \mathrm{g} \mathrm{L}^{-1}$ and $7 \mathrm{mg} \mathrm{L}^{-1}$, respectively. The accuracy was evaluated by addition and recovery tests.

Three water samples were analyzed before and after a $300 \mu \mathrm{g} \mathrm{L}^{-1}$ sulfate addition. The addition and recovery tests presented results between 98 up to $101 \%$ (Table 1), thus confirming that the proposed method can be successfully applied in the analysis of sulfate ions in water samples. The sulfate concentration found in water samples is in accordance with CONAMA $^{13}$, which determines $250 \mathrm{mg} \mathrm{L}^{-1}$ to be the maximum sulfate concentration.

\section{Conclusions}

The proposed FIA system allows sulfate determination without any previous sample treatment. The main system characteristics were an analytical frequency of 6 readings per hour; LOD = $1.00 \mu \mathrm{g} \mathrm{L}^{-1}$ and LOQ $=3.33 \mu \mathrm{g} \mathrm{L}^{-1}$, precision estimated as the maximum standard deviation of 0.8 for triplicate runs. There was no significant interference for common concomitants found in water samples. The accuracy was estimated to be between 98 and $101 \%$ in recovery tests. The method presented satisfactory results when applied in both dam and mine water samples.

\section{Acknowledgements}

The authors thank FAPEMIG, CNPq, FURNAS and CAPES for financial support and fellowships. We would also like to thank Mr. Azenilto G. Brito for English revision.

\section{References}

1. C. R. Martins and J. B. Andrade, Quím. Nova, 2002, 25, 259.

2. L. A. Komarnisky, R. J. Christopherson, and T. K. Basu, Nutrition, 2003, 19, 54.

3. R. G. WETZEL, "Limnologia", 1983, Sauders College Publishing.

4. American Public Health Association, "Standard Methods for the Examination of Water and Wastewater", 20th ed., 1998, Washington, D.C.

5. J. A. Vieira, I. M. Raimundo Jr, and B. F. Reis, Anal. Chim. Acta, 2001, 438, 75.

6. M. C. Gennaro, C. Abrigo, G. Saini, H. Muntau, G. Serrini, and H. Geiss, Fresenius J. Anal. Chem., 1994, 350, 702.

7. B. Raue, H. J. Brauch, and F. H. Frimmel, Fresenius J. Anal. Chem., 1991, 340, 395.

8. G. F. Lima, A. M. Brondi, A. L. S. F. Paiva, C. R. T. Tarley, A. F. Oliveira, C. Wisniewski, and P. O. Luccas, Anal. Sci., 2011, 27, 309.

9. T. D. Rees, A. B. Gyllenspetz, and A. C. Docherty, Analyst, 1971, 96, 201.

10. C. M. Johnson and H. Nishita, Anal. Chem., 1952, 24, 736.

11. D. D. Siemer, Anal. Chem., 1980, 52, 1971.

12. R. F. Teófilo and M. M. C. Ferreira, Quím. Nova, 2006, 29, 338.

13. T. Lundstedt, E. Seifert, L. Abramo, B. Thelin, A. Nyström, J. Pettersen, and R. Bergman, Chemometr. Intell. Lab., 1998, $42,3$.

14. CONAMA (National Council on the Environment, Brazilian), Resolution No. 357 of March 15, 2005, http:// www.mma.gov.br/conama/legiano.cfm? codlegitipo $=3$.

15. Analytical Methods Committee, Analyst, 1987, 112, 199. 